\title{
Mhjournal
}

\section{Sociedad e Identidad en el audiovisual latinoamericano y español}

Ricardo Jimeno Aranda | rijimeno@ucm.es

Universidad Complutense de Madrid

Gabriela Fabbro|gfabbro@austral.edu.ar

Universidad Austral

A lo largo del siglo XX, los medios audiovisuales han sido los constructores más potentes de imaginarios sociales e identitarios. En el siglo XXI, la realidad de la globalización, la generalización de Internet y de las redes sociales y el surgimiento de las plataformas de consumo online han impulsado exponencialmente el intercambio cultural de dichos imaginarios. Se ha conformado así una cultura global que aglutina, de forma paradójica, la homogeneidad y la diversidad. Como explican Mercado y Hernández Oliva (2010, p. 229), "el proceso de globalización ha generado, por un lado, nuevas identidades como resultado de la apertura de fronteras y por otro, la reivindicación de lo propio, por parte de ciertos grupos que se resisten a abandonar su cultura".

Por este motivo, ante esta peculiar paradoja que muestra la tensión en conflicto entre la transversalidad y la homogeneidad social, en la que la tecnología y el audiovisual tienen un papel sustancial, y la defensa de la identidad y el resurgimiento de los nacionalismos se redefinen y consolidan, este monográfico intenta responder a algunas cuestiones que se plantean en torno a la construcción de los imaginarios audiovisuales en diferentes periodos, tanto en momentos históricos clave del siglo pasado como en otros más recientes, en los espacios geopolíticos aludidos. El diálogo constante entre el pasado y el presente se manifiesta como una cuestión fundamental para entender precisamente el devenir de nuestras sociedades, así como el intercambio cultural e ideológico en el ámbito latinoamericano y español, sujeto también a dinámicas cambiantes en función de la evolución histórica y sociopolítica de los diferentes Estados y regiones e incluso de los procesos de revisión del pasado histórico, o las diversas realidades sociales en conflicto. Como explican Pérez Morán y Sánchez Noriega, "El cine, cada vez más versátil en formatos y soportes de exhibición, surge en una sociedad determinada de las que las películas son, inevitablemente, testimonio al tiempo que contribuyen a alumbrar nuevos valores o reforzar los emergentes" (2021, p. 11). Una idea que evidentemente puede extrapolarse del medio cinematográfico a otras formas audiovisuales, tanto más si algunas de ellas pretenden ser una mediación directa de lo real. Esta realidad compleja ha sido analizada en diversos estudios que tienen como 
marco de actuación el ámbito de la producción audiovisual, tanto en su forma tradicional, cinematográfica y televisiva como en nuevos canales y formatos, o en el ámbito del cine experimental.

Entre los estudios presentes en el monográfico, puede hallarse en el ámbito del cine una aproximación heterogénea a diversos cines nacionales (español, argentino, mexicano) que aplica perspectivas diferentes, centradas particularmente en la manera en que son reflejados determinados sectores sociales, estereotipos o imaginarios culturales nacionales. Así Lucía Vázquez Rodríguez y su equipo toman en cuenta la forma de representación de las mujeres encargadas de los cuidados en el cine latinoamericano contemporáneo, utilizando como casos de estudio las películas Roma (Alfonso Cuarón, 2018) y La ciénaga (Lucrecia Martel, 2001), lo que premia una mirada que incide en la perspectiva social y de género dentro de la construcción narrativa de ambos filmes, cuyo punto de vista está dominado por personajes femeninos con dicha ocupación laboral. Por su parte, Luis Sanguinet rastrea precisamente en el pasado histórico, en concreto en el punto de inflexión del franquismo, entre el nacionalcatolicismo y el inicio del desarrollismo, para observar la mirada sobre lo español que ofrecía el desembarco de cineastas norteamericanos que utilizaban España como plató de rodaje y escenario exótico, en concreto a partir del análisis de Aventura para dos (Spanish Affair, 1958), dirigida por Don Siegel y con Carmen Sevilla como protagonista.

En el área de la televisión, otra serie de estudios recogen miradas retrospectivas o actuales, algunas recientes sobre el pasado histórico, que amplifican el diálogo expuesto. Las perspectivas varían entre los casos singulares de ficción que siguen el patrón comentado, analizando modelos de representación social y construcción de estereotipos, como el que lleva a cabo Lucas Martins Néia tomando como base de estudio la telenovela brasileña contemporánea, o transitando hacia el espacio político, dentro del campo de la ficción, como hace Janny Amaya Trujillo, para observar cómo se han reconstruido los procesos de contestación estudiantil de los años sesenta en México a través de las series emitidas en las plataformas de video bajo demanda.

En el ámbito del audiovisual más experimental y radical, Esther Pérez Nieto aborda la obra de la documentalista española afincada en México, Nuria Ibáñez, y de Laura Herrero, cineasta española cuya ópera prima, también en el campo del documental, El remolino (2016), se ambienta igualmente en México, abordando la vida de una comunidad campesina en Chiapas. En ambos casos, la representación del espacio emerge como el elemento primordial de las obras, por encima de las convenciones narrativas.

La homogeneidad y la diversidad, la ficción cinematográfica y televisiva, el género documental y los cines nacionales nos acompañan en este recorrido que invita a la lectura y a la reflexión, poniendo en evidencia la complejidad del contexto de los contenidos audiovisuales actuales y de las múltiples formas de interpretarlo y resignificarlo. Preguntarnos por la identidad, local y global, y cómo los imaginarios colectivos colaboran en su construcción y formación es el desafío que intenta en parte responder este monográfico. Los invitamos a transitarlo. 
MHJournal Vol. 13 (1) | Año 2022 - Prólogo - Páginas 15 a 18 - mhjournal.org

\section{Bibliografía}

Mercado Maldonado, A., y Hernández Oliva, A. V. (2010). El proceso de construcción de la identidad colectiva. Convergencia, 17 (53), 229-251.

Pérez Morán, E. y Sánchez Noriega, J. L. (2021). Resistencias y disidencias en el cine español: el compromiso con la realidad. Madrid: Ediciones Complutense. 
MHJournal Vol. 13 (1) | Año 2022 - Prólogo - Páginas 15 a 18 - mhjournal.org

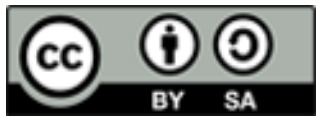

Licencia Creative Commons

Miguel Hernández Communication Journal

mhcj.es

\section{Cómo citar este texto:}

Ricardo Jimeno Aranda y Gabriela Fabbro (2022): “Sociedad e Identidad en el audiovisual latinoamericano y español”, en Miguel Hernández Communication Journal, Vol. 13, páginas 15 a 18 Universidad Miguel Hernández, UMH (Elche-Alicante). DOI: 1021134/mhioumalv13i.1528 